\title{
Polanyi Symposium: a conversation on embeddedness
}

\author{
Greta Krippner, Mark Granovetter, Fred Block, Nicole Biggart, \\ Tom Beamish, Youtien Hsing, Gillian Hart, Giovanni Arrighi, Margie \\ Mendell, John Hall, Michael Burawoy, Steve Vogel and Sean O'Riain*
}

Affiliations and correspondence: see cast of characters, p. 134

\begin{abstract}
This conversation, transcribed from a conference in April 2002, is intended to illuminate current debates about the use and abuse of the embeddedness concept in economic sociology.
\end{abstract}

Keywords: embeddedness, markets, economic sociology

JEL classification: B520 current heterodox approaches: institutional; evolutionary, L230 organization of production

\section{Introduction}

In April 2002, an interdisciplinary group of scholars gathered at the University of California Davis for a conference on 'The Next Great Transformation? Karl Polanyi and the Critique of Globalization. The conference was organized by Fred Block, Nicole Biggart and Sean O'Riain and was made possible by support from the University of California's Institute for Global Cooperation and Change, the UC Davis Institute for Government Affairs, and UCD's Center for History, Society, and Culture. The conference was based on the premise that economic sociology and other contemporary studies of global transformation could be enriched by a more systematic engagement with Polanyi's thought. Most of the conference was organized around 10 papers, some of which were more empirical and some more theoretical. Three of these papers have been published in revised form in a special issue of Politics \& Society in June 2003. The conference organizers decided to devote one session to a more open conversation designed to clarify the embeddedness concept. The choice of topics seemed obvious since there were clear tensions

\footnotetext{
${ }^{\star}$ Authors are listed in order of appearance.
} 
between Polanyi's initial use of the concept and its use today. We invited Greta Krippner to begin the session since she had recently published an article, 'The Elusive Market: Embeddedness and the Paradigm of Economic Sociology', that represented a strong critique of how several scholars had deployed the embeddedness concept. The floor was then turned over to Mark Granovetter and Fred Block, both of whom were targets of Krippner's critique (Krippner, 2001, pp. 775-810). The last pre-arranged speakers were Nicole Biggart and Tom Beamish, who had recently completed a study of the embeddedness of the market for commercial buildings. Then the floor was thrown open for a free-wheeling discussion. The transcript that follows is an edited version of both the prepared remarks and some of the discussion. We are deeply grateful to Matt Keller for transcribing and editing the transcript and to David Marsden for editing and shortening the manuscript.

\section{Opening remarks on embeddedness}

\subsection{Greta Krippner}

More than most subfields of sociology, economic sociology is built on one key idea. That is 'embeddedness', first formulated by Polanyi and subsequently recovered from Polanyi's writings and reconstructed for the purposes of economic sociology by Mark Granovetter. My purpose in this essay is to turn a critical eye on the way in which economic sociology has been shaped by the idea of embeddedness. In particular, I want to explore a paradox: the basic intuition that markets are socially embedded has led economic sociologists to take the market itself for granted. The result is a curious underdevelopment of the concept of the market in economic sociology. In order to understand this paradox, it is necessary to revisit, briefly, Granovetter's formulation. His concept of embeddedness attempted to steer an intermediate course between what he referred to as 'under-' and 'oversocialized' views of social action. The first phrase refers to neoclassical economics, in which social outcomes are analysed as resulting from the aggregation of actions made by isolated rational decision-makers. The second phrase was coined by Dennis Wrong to reference the tendency in sociology deriving from Parsons to portray individuals as compelled to act by a set of norms and values that are thoroughly internalized. Granovetter argued that both positions are flawed, and his concept of embeddedness attempted to avoid the atomism implicit in both formulations by suggesting that social action is 'embedded' in ongoing networks of social relations. But while his stylized contrast of under- and oversocialized views correctly identified one way in which these two seemingly disparate approaches were similar, Granovetter overlooked another: both Parsonian sociology and neoclassical economics share in common not only atomism, but also a vision of the social world as sharply demarcated into neatly bounded and essentially separate realms. 
Herein lies the source of the paradox: Polanyi's original concept of embeddedness was explicitly intended to undermine incipient disciplinary boundaries by portraying social processes in terms of a fluid mixing of 'economic' and 'non-economic' factors. But the work that such a concept could perform was transformed in a post-Parsonian intellectual landscape in which these once-porous boundaries had hardened into impermeable divisions. Indeed, the enduring influence of Parsonian sociology remains - even after Parsons functionalism has been roundly rejected - in the ease with which contemporary sociologists speak of the economic and the social as though they occupy entirely disjoint positions in an abstract topography. I argue that economic sociology has not come to terms with this legacy of its intellectual forbears, in spite of Granovetter's laudable attempt to set the 'new' economic sociology apart from both the 'old' economic sociology of Parsons and Smelser and from neoclassical economics.

Let me briefly elaborate this argument by providing two illustrations. Consider, first, Fred Block's invocation of embeddedness in his attempt to reconstruct the market concept in Postindustrial Possibilities. Block's specific intervention revolves around the suggestion that economic sociologists ought to begin to think of the market as a variable, something more or less present. Such a conceptual shift, Block argues, would allow researchers to assess the 'marketness' of given societies or historical periods (Block, 1990, p. 51). To aid in comparative work of this kind, Block defines a continuum extending from 'high marketness' - corresponding to the competitive market of economic theory-to 'low marketness' - corresponding to organizational hierarchies. He explains: 'High marketness means that there is nothing to interfere with the dominance of price considerations, but as one moves down the continuum to lower levels of marketness, nonprice considerations take on greater importance' (Block, 1990, p. 53).

One problem with this strategy is that 'social' factors enter into the analysis only as one moves away from the market end of the continuum, preserving intact the asocial market construct. Block notes, 'As the marketness of transactions diminishes, economic behaviour tends to become embedded in a more complex web of social relations' (Block, 1990, pp. 50-1) - as if markets themselves did not represent 'complex social relations'. Block's difficulties here are symptomatic of a broader tendency in economic sociology to conflate the duration of a market relationship with the degree to which it is 'social'. Block notes: 'The term market should be reserved for situations in which relatively independent actors come together to make economic transactions of limited duration.' Contrasted against this definition are all of the various transactions that are not instantaneous but ongoingthe relationship between a worker and her employer, between a lead firm and its supplier, between a preferred business and its loyal customer base. These relationships are social in a very literal sense: they often involve ties of friendship or even family, they are enacted through social engagements which extend beyond the spatial and temporal confines of the business day, and they may illicit intense 
feelings of loyalty. The problem with this line of argument is that it leaves the hard core of instantaneous market transacting outside of the realm of economic sociology. The strategy of economic sociology—here exemplified by Block's construction of 'marketness' - has been to whittle away at the market construct, revealing that an ever-greater share of transactions are enacted through social relationships. But every transaction, no matter how instantaneous, is social in the broader sense of the term: congealed into every market exchange is a history of struggle and contestation that has produced actors with certain understandings of themselves and the world which predispose them to exchange under a certain set of social rules and not another. In this sense, the state, culture and politics are contained in every market act; they do not variably exert their influence on some kinds of markets more than others.

As a second, quite different example, consider the work of network theorists such as Wayne Baker and Ronald Burt. These researchers, also working under the banner of embeddedness, theorize various properties of markets by mapping out the complex patterns formed by network ties. Scholars such as Baker and Burt are explicit that, while markets could be considered in other aspects, the structural dimension of market relations is paramount. In this respect, the theoretical project of network theory is hardly less abstract than that of neoclassical economics: a single aspect of human behaviour, here the basic drive toward connectivity, is isolated from a broader range of social processes and afforded a strategic role in analysis. As Brain Uzzi has commented regarding Burt's work, 'A network structure rich in structural holes is virtually all that is needed to induce information and resources to flow through the network like electric current through a circuit board' (Uzzi, 1997, p. 63). This austere style of theorizing is deliberate, constituting part of a strategy to avoid the 'traps' of categorical thinking. Indeed, in building a relational social theory, network theorists jettison the typical list of variables of interest to social scientists, such as race, ethnicity, gender and class, arguing that such attributes are merely the spurious correlates of network structures. The problem with this approach, as Powell and Smith-Doerr (1994, p. 371) have argued, is a certain 'primacy of method over substance'. They suggest the need to bring back in 'the content of ties, rather than merely the structure formed by those ties'. In short, this work suffers from the opposite problem to that of Block's 'marketness' construct. Block's formulation layered a social economy on top of a pre-social and untheorized market. In contrast, network theorists such as Baker and Burt explicitly examine the market, but social content is distilled away from social structure. As Fligstein (1996, p. 657) notes, 'networks are sparse social structures', devoid of politics and culture.

In conclusion, I argue that the concept of embeddedness has contributed to the lack of an adequate theorization of the market in economic sociology. In attempting to steer an intermediate course between the twin perils of under- and oversocialized views of action, Granovetter has run the ship aground on a conception, common to 
both, that insists on the separate nature of economy and society. This problem manifests itself in a curious symmetry that exists in the subfield: researchers either study economic processes in social terms, in which case they abandon the sphere of the market; or, they study the market as a theoretical entity in its own right, in which case they purge all social content. The lesson of these various endeavours is that as long as the market is not fully appropriated as a social object, there will be a tension between, on the one hand, marketless conceptions of the social, and on the other, conceptions of economy in which every social trace is suppressed. In either case, economic sociology will find itself in the paradoxical position of propping up the asocial market model of neoclassical economics. Where such paradoxes abound, rethinking the central premises of our discipline becomes an arduous and pressing task.

\subsection{Mark Granovetter}

Greta Krippner has written an eloquent paper. The part where I take issue is the question: if indeed intellectual crimes have been committed, which may be the case, then where does the ultimate responsibility lie? The following analogy occurs to me: Suppose you saw someone walking down the street wearing a cheap, badly made knockoff of an Armani suit. Would you then say: 'ooh, that Armani, what a terrible designer!' Or might you say instead: 'poor Armani, look what they've done to his design!'

So the question I want to raise is whether the problems Krippner identifies lie in the way I changed the meaning of 'embeddedness' from Karl Polanyi's usage, or perhaps instead in the way subsequent writers used or misused the term. If you look at my writings in recent years, I rarely use 'embeddedness' any more, because it has become almost meaningless, stretched to mean almost anything, so that it therefore means nothing.

But let me come back to my original usage, and talk about what I meant by it and how I came to use it. It is certainly true, as Greta Krippner notes, that in the 1985 paper that she analyses, I use the term 'embeddedness' in a narrower and somewhat different way than Polanyi meant it. The reason is that I was not trying to borrow the term from Polanyi, or to re-appropriate it or to reintroduce it. Something more complicated was going on. I have looked back in my old notebooks and found that I used the term embeddedness in some of my very early notes, before I ever read Polanyi. And I used it in the way that I use it in the 1985 paper to mean the way social and economic activities are mixed up with networks of social relations. I would guess that I picked up the term embeddedness from Harrison White's lectures when I was a graduate student, but I can't be absolutely sure of that. I know that at some later time I did read Polanyi. I read particularly 'The Economy as Instituted Process' (Polanyi, 1957) It was not until much later that I really carefully read The Great Transformation. 
But then when I came around to writing the paper on embeddedness (Granovetter, 1985), I had, in fact, forgotten about Polanyi, and was not thinking about him when I wrote that paper. I used the term pretty much as I had used it in my old notebooks. I was a little embarrassed, maybe a lot embarrassed, when the paper was not yet published, but pretty far along and there were drafts circulating around, and I got a note from Wayne Baker. He had recently gotten his Ph.D. at Northwestern where he would have been exposed to all the substantivist anthropologists there, and hence to Polanyi and his ideas. Wayne Baker said something in his letter to the effect of 'oh, I see you've revived Polanyi's usage of embeddedness'. And I read the letter and I thought 'oh my gosh, I'd completely forgotten that Polanyi uses it, and uses in a somewhat different way'. So I did say a little bit in the paper on embeddedness about Polanyi, but the main thing I was trying to do in that little section was to distance myself from his use of embeddedness because I was using it in a different way and I thought that, certainly in The Great Transformation, there was an ambivalence about the extent to which the 19th century economy was embedded or disembedded. There are a couple of distinguishable positions there. So, the fact that it is used differently is not because I was really doing this in dialogue with Polanyi. I was just using it in a different way.

Let me respond to one of the most serious issues raised by Greta Krippner, which is that the goal of my paper was to advocate the analysis of social networks as the main or the only goal of economic sociology, rather as Parsons had advocated the analysis of values as the main or only activity of sociology. Now I think it is true that Talcott Parsons sacrificed sociology on the altar of consensually held values, but I don't think anything like that has happened in my paper, at least not knowingly so.

The argument that, in doing economic sociology, one should only analyse the structural aspects of social networks, is such an extreme and foolish position, that I am not sure anyone has ever actually taken it; and certainly I know that I would never have done so. If you look at the corpus of my work, it seems to me that from the beginning I've been very clear that it was a strategic research decision to look at social networks as an intermediate level between lower levels and higher levels. So the question might be: if indeed the paper had the impact of concentrating people's energy on the analysis of social networks as the only thing to look at in economic sociology (which is arguable), you may ask: then why did I not say in the paper what I thought and what I knew then and know now, namely that you can't just analyse social networks, you also have to analyse institutions and culture and politics and all of the micro and macro elements, of which the 'meso-level' of social networks is in the middle?

I have two answers to that. One is that, in a way, I did. On page 506, I said, at the end of the paper: 'Finally, I should add, that the level of causal analysis adopted in the embeddedness argument is a rather proximate one. I have had little to say about what broad historical or macro-structural circumstances have led systems to display the social structural characteristics which they have. So I make no claims for this analysis 
to answer large-scale questions about the nature of modern society or the sources of economic and political change. But the focus on proximate causes is intentional. For these broader questions cannot be satisfactorily addressed without more detailed understandings of the mechanisms by which sweeping change has its effects. My claim is that one of the most important and least analysed of such mechanisms is the impact of such change on the social relations in which economic life is embedded. If this is so, no adequate link between macro and micro level theories can be established without a much fuller understanding of these relations.' So the argument was that this is at least a necessary condition for understanding the larger picture. It clearly was not a sufficient explanation, but I did not say much more than that.

To see why I did not say more, you have to think of where I was, writing this paper between 1981 and 1984, what I was thinking, what I was trying to do. I was not sitting there thinking: 'how should I set the agenda for economic sociology for the next 15 years?' Or: 'I'd better say this very carefully because this is going to set the agenda for economic sociology for the next 15 years.' Who could imagine it would have that effect or that anyone would imagine it would have that effect? I was just trying to get the thing published. It was not easy because I got a very critical round of revise and resubmits from AJS, and then when I revised and resubmitted it, the reviewers were still quite split. The editor saved my day and decided to publish it. The paper focused on a somewhat narrow range of problems, having to do with the way social networks function in the economy. I was also reacting against the functionalist economism of writers like Oliver Williamson and Marxist economists, like Samuel Bowles and Herbert Gintis, which relied on Hobbesian ideas or tautologies like 'class culture'. Maybe if I had known it would be an influential paper I would have taken more care to say that there's more to life than the structure of social networks. But it really never occurred to me that I had to worry about that.

This raises important substantive issues. If we agree that all market activity is social, it's always embedded in something, then we do need to talk a lot more systematically than we have about what that something is in situations where market relations actually are more or less impersonal. This relates, for example, to some of the discussion that Greta Krippner has of Brian Uzzi's work. I think that what we need to think more about is this: even when markets are impersonal—and they are not mixed up with personal relationships — they are still embedded in a larger institutional framework, and a culture, and a set of rules and situations that have somehow been put there by a social process.

There is a wonderful paper by Donald MacKenzie and Yuval Millo (2003) on the origins of financial derivatives exchanges at the Chicago Board Options Exchange. Though these trades are carried out in a very impersonal way, through machines and so on, they show that one needs a social network analysis to understand how this exchange came into being. One of the very fascinating findings is that when people first started to think about trading options, which are a form of derivatives, 
most actors associated it with gambling and therefore thought that such trading should not be a part of an official exchange. So they give a very interesting historical account. They interviewed a lot of the principals and asked them whom they talked to and whom they influenced and how this all played out, and how they re-defined the situation in such a way that a derivative was seen as a legitimate financial instrument rather than something you would do in Las Vegas at a gambling table and so made it possible to make this a 'real' exchange.

That fascinating analysis reminded me of Viviana Zelizer's work (Zelizer, 1979) on how life insurance became a commodity. The way she did this in her argument is interesting. She used archival material—brochures from life insurance companies, copies of speeches that various pastors gave talking about life insurance-and she gave it a completely cultural and religious explanation. She could not go back and interview all these people and follow out the networks through which these messages travelled and the way people influenced each other, because, of course, these people are no longer living. But because she does not, it tends to give the impression that this all is a purely cultural phenomenon rather than a social network phenomenon when in fact all cultural phenomena are also social network phenomena, and vice versa-you can't separate the two. So if this had happened in the 20th century, as did MacKenzie's case, you could do the cultural analysis at the same time as you understood who the key actors were and how that influence travelled through social networks, and you would have a very interesting and much more complete picture, because networks are always involved.

When I gave my keynote address at the social networks conference in 1990, which was called 'The Myth of Social Network Analysis as a Separate Method in the Social Sciences', I urged those doing narrowly quantitative and structural social network analysis to think about the larger setting in which social networks operated, to think about how they were really a middle ground between larger cultural and political and economic phenomena at the macro level of institutions and individuals at the other side. They were the sort of central, proximate causal level through which all these connections were flowing back and forth. That is one of the reasons why two of my favourite examples of network analysis in economic sociology are two books by Michael Burawoy, Manufacturing Consent and The Politics of Production (Burawoy, 1970, 1985). The network analysis is informal, and is embedded in a much larger structure and discussion about the politics and the economy and the culture and the history of these systems.

So, this is to say again that, in my view, networks are only interesting because they are a mediating proximate cause. In a recent paper, called 'Toward a Theoretical Framework for Economic Sociology' (Granovetter, 2002), I argue this point again and elaborate by suggesting that networks are only interesting because they are where cooperation and trust and domination and compliance are actually produced, and those are crucial parts of every socio-economic system. But if you only 
look at the level of networks rather than at the more macroscopic or the more microscopic levels then you have no clue about how or why this production takes place. So I think that has always been my emphasis. In my first published article, which I wrote in draft when I was a graduate student, called 'The Strength of Weak Ties' (Granovetter, 1973), I went on at some length about how networks were interesting because they were the middle ground between micro and macro and that a great deficiency in sociological theory was not to tie the micro and macro together. So that has always been my intention and always been my argument, and I would certainly like to underline that today.

\subsection{Fred Block}

I follow right on Mark, but my defence has a much more complicated task than Mark because I cannot make the argument that I had not read Polanyi or hadn't remembered him. I think the proper response is to not bury the embeddedness concept but to try to strengthen it and try to improve it, and if what was a problem here was essentially a too 'thin' concept of 'embeddedness', then we need a 'thicker' concept of embeddedness.

As I struggled to think about these issues it did force me to go back to The Great Transformation, and try to tease out more carefully what Polanyi's own argument was, and the complexity and difficulty that we've all had attempting to appropriate it in some reasonable way. The short version of the argument that I make in the paper 'Karl Polanyi and the Writing of the Great Transformation' (Block, 2003) is one that I'm going to frame in archaic Althusserian terms, that in the process of writing The Great Transformation, Polanyi's thinking went through an epistemological break, in that the original problematic that he had used to frame the manuscript was based upon his thinking in the mid- to late 1930s. In the process of writing that book, he moved from the Hegelian Marxism, point A, to a point B, and his fundamental thinking about the nature of the economy changed and, in Althusserian terms, I would put it that he 'discovered the lost continent' of the always embedded market economy. He made the discovery, which is there in the text, but he was unable to name it. It is buried in the text and in the original frame of the book. There are profound tensions in the text between, on the one hand, a kind of determinism that is very evocative of Marxism in the original construction, crisis and collapse of market society; and on the other, the view toward which he was evolving, 'the always embedded market economy'. However, the latter cannot have the same kind of deterministic logic as a Marxist mode of production argument.

Now, my argument, and I have textual support for this, is that Polanyi was writing the book against a self-imposed deadline, which was that he needed to get the book into print before the end of the second World War. He was trying to influence the post-war settlement. His negative example was John Maynard Keynes, whose 
Economic Consequences of the Peace (Keynes, 1919) came after the damage had been done. So he didn't have time to resolve the theoretical tensions in the text, and we have been left ever since to sort through an internally contradictory text. It seems to me that the task for us now is to take this implicit notion of the 'always embedded market economy' and reinvigorate it, to use it to elaborate a thick conception of embeddedness. One of the elements of this thick concept, on which I shall not spend much time because I think there is a consensus in the room, is that markets are always politically embedded. They require a set of legal rules, a set of institutions, and so on. Such political embeddedness exists at both the national and global levels: there are at particular times these global regimes that are politically structured as Giovanni and Beverly have emphasized in their paper (Silver and Arrighi, 2003).

In elaborating this thicker concept of embeddedness, we want to make it a dynamic and not a static concept. So in thinking about that political embeddedness, we have a lot of material to work with, in that there are a variety of strands of argument (like social structures of accumulation, regulation school, and so on) which give us the basis of the arguments that these political structurings of markets have limited time frames. They can work for 20,30, 40 years, then they come into crisis, and enter periods when they need renewal. That is one of the fundamental dynamisms in the nature of political embeddedness.

The second dimension of embeddedness, we have not talked very much about. Eileen Otis mentioned it (Otis, 2002), talking about the 'moral economy' in the Chinese hotel. This also goes to Greta's point. In our rebellion against Parsonian functionalism and free-floating norms and internalized morality, we found it very difficult to talk about norms and moral order. It seems to me that we fundamentally have to stress that these markets are always morally embedded. They might be morally embedded in a better or worse way. This is an insight that the negative cases remind us of - my favourite case that you might have seen is of the pharmacist in Kansas City who pled guilty to 120 counts of diluting cancer medication for his patients. At the sentencing hearing they said: 'why did you do it?' and he said 'well I had a big tax bill and I had pledged a million dollars to the church building fund, and I had another payment coming. Here's an example of the moral economy not working, someone who's a little bit unclear on the relationship between theory and practice. These violations are becoming more visible because it is market society's guilty secret that it is fundamentally dependent upon a moral order. This is precisely where Polanyi's critique of the naturalism of economics is relevant. That tradition of economic thinking, from Malthus and Ricardo to the present, puts morality outside of the economy by naturalizing economic behaviour, and by seeing people responding to market signals as never being morally problematic, but simply as engaging in a rational calculus. We have this erosion as a consequence of the last 30 years of celebrating that 'greed is good' and that the market works. This is an argument that others have made before-Fred Hirsch's Social Limits to Growth 
(Hirsch, 1976) talks about precisely the market economy undermining the moral understandings that make it possible. But the reason that this moral embeddedness is so fundamental, and this follows exactly on from Mark's observations about even the most impersonal markets, is that even these impersonal markets collapse almost immediately if people do not do what they learned to do in kindergarten, which is to play by the rules, take turns, don't hit. Or the other way of saying it is that trust is the lubricant for all market transactions, and when moral violations are always present, that trust evaporates and the market lacks the lubrication. We have seen a very graphic example of this in the post-Soviet experience where this set of shared moral understandings was lacking. So it is not simply a question of legal regulation and rules, because if these moral understandings are not widespread then there's a problem.

\section{Embeddedness in energy-efficient construction}

\subsection{Nicole Biggart}

When Mark's influential paper came out in the mid-1980s (Granovetter, 1985), it was a solution to a problem for me and for many young sociologists (I was an assistant professor at the time) who were just moving into business schools. We heard many talks by professors of finance, accounting and economics, and very often they would open with: 'assume a market'. To a sociologist what does 'assume a market' mean? Well, of course they were talking about a neoclassical market, which is a set of four assumptions: perfect information, independent firms and actors, homogeneous products and rational actors with complete information. There was no presumption that a market was a real place, but rather that it was a construct, a useful fiction against which one could then talk about sometimes real markets, sometimes logical markets. But everyone knew where that person was starting from when they said 'assume a market.' I wondered what it would be like if a sociologist said: 'assume a society'. One could not do it. And because economists were and are very powerful, certainly in business schools, we would talk about how one can have a better understanding, or how can we start conceptualizing a market that has social relationships, because for economists, a market that has social relationships of any type, including competitive relationships, is an imperfect market. A logically perfect market, after all, has no social relationships: any time you get two people to talk to each other in a market, then you have something nasty like collusion.

So when Mark's paper came out and proposed the idea of markets as 'embedded', it provided us with an opportunity to begin to think about markets as something other than a conceptually socially empty category — which may make perfect sense for the purposes of economics, but not for us. 
In fact, I think there had been a lot of interesting work from a network perspective, a network-structural perspective, on embeddedness. A very interesting paper came out in 1990, just a few years after Mark's paper, written by Sharon Zukin and Paul DiMaggio (1990), proposing four types of embeddedness. One of these was structural, which we ran with, I suspect for methodological reasons, because it is a lot easier to apply mathematical methodologies to a structural understanding of embeddedness. But they talked about three other aspects of embeddness: one being 'political', 'cognitive' and 'cultural.' I think we have not developed these other elements, which to use Fred's words, would be to 'thicken' the concept. I think we are overdue for it, and I want to share a bit from a study by Tom Beamish and myself (Lutzenhizer et al., 2001). It was funded by the California Institute for Energy Efficiency. They had a question that I think is important, if mundane: why are skyscrapers not more energy efficient as existing technology would allow them to be? Why don't they take energy efficient technology—better insulation, heating ventilation systems, and so on, that is available off the shelf and install it in these buildings? This is not unimportant because, after automobiles, commercial buildings are the biggest users of energy.

We did the study-another team took in the Pacific Northwest and Tom and I, the Sacramento region. We did fieldwork, archival work, tried to understand the professional arrangements in this market setting. In fact, we were not the first people given this question. They had first asked economists, and they said that when the price of energy gets high enough, then people will care, which did not seem to hold true through business cycles. Some anthropologists studied architects and said it was caused by their occupational culture, very concerned with aesthetics and less with functionality. They spent a lot of money teaching architects about these new technologies. It turns out they knew all about them, but still did not install them. Then they gave money to us to see what we had to say. Too hot, too cold, I think we were just right.

We went out and started talking to people, and my first interest was to understand how this market was structured, how it was put together, what are the relationships between the actors involved. Building a commercial building is an extremely complex project. So many different people become involved: everything from developers, mortgage bankers, appraisers, designers, all the trades, people who zone, inspect, and so on. It is amazing that these things even happen. It is especially amazing since most of these buildings are done once and then the design is thrown away and never reproduced in precisely the same way. Most of the actors are in market relationship to each other, so you have very complex, financially very expensive and very risky projects, and no one is in charge, and they take years. So in Fred's language, 'high marketness' is involved in this setting.

One of the answers is that when you have market relations rather than authoritative relations structuring these projects, actors avoid anything new because the 
market comes to depend upon routines and conventions of a variety of sources. These include routinized relationships between market actors. This market, in fact, depends upon and really requires shared understandings among these actors. They use shorthand, they have a special language, they have ways of judging how well the other actors know what's going on, whether they can be trusted-not necessarily in a personal sense, but in a professional sense- to do the right thing, which is basically: do not take any more time, do not cost us any more, do what needs to be done and no more. We talk about this as a sense-making regime that takes place in this market, and the paper, which is on the web, discusses some of the ways these sensemaking elements work together to ensure, as an actor, that I know you are part of this sense-making regime, that you are part of a community of practice. This helps to reassure them that this expensive and risky project will go as they expect, and that there will be no surprises.

I think one of the interesting things was that Tom and I were really going out into this marketplace trying to understand something about a bricks and mortar product that they were constructing. There is nothing more bricks and mortar than a skyscraper, one would think. Embarrassingly for us, it took us at least three or four months to realize that the actors in this marketplace were not building material objects, or at least that is not the primary way in which they think of buildings. Buildings for them are investments, and this includes even those who construct them. Skyscrapers in this country, since around the 1960s and 1970s, have been securitized. Most buildings are leased, and they are owned by large development firms and often sold as real estate investment trusts. They're put into real estate investment trusts and they're owned by large pension funds in this country. So the logic of this securitized pass-through for investment income-you want to have lease money that will start today and will continue for 15, 20, 30 years in a way that does not surprise anyone. It becomes a conservative part of someone's investment portfolio to balance out the bonds and the stocks-you want a steady stream of income. A new heating, ventilation and cooling system messes this up because you do not know how it is going to perform over the long run. The people who are putting the building together have to forge a new relationship with a contractor or sub-contractor who may not be known to them; they have to find a new person to maintain it, and they want to be sure it is not going to affect the income stream one way or another for the person who actually owns the building. So there is a whole range of reasons, based on the structure of the market and the marketization of this product, which, in this case, militate against energy efficiency, and this sort of innovation.

It took us a while to understand that what appeared to be the exchange of goods and services in the production of a material object in fact is eminently immaterial, based on a resolutely market logic. This market concept totally organizes the relationships of all these actors around something that would seem to be as far from a security as an immaterial object can be. 
I shall not talk about the ways in which this sense-making regime works, but just want to suggest that I think that this kind of 'on-the-ground' examination of markets begins to get into the heads, the understanding, of the actors involved, which gives us a more dynamic view of market structure, how markets are put together, and to what consequences.

\subsection{Tom Beamish}

I think you've given a good sense of the argument. Some of the things that might tie this together into the larger discussion are the place of this investment paradigm as a structuring device, something that structures the relationship, and that this process of building is very path dependent. So you can imagine coming into a project where the person or the project before you has introduced uncertainty into a project that must unfold. There is a relationship between global ends, or a larger structure, that the investment paradigm as a global end which is about stability, survival, prosperity, and the local means of attaining them. So what you get are these sense-making regimes which allow one to look backwards, in a historical sense, at how they have interacted with persons and created a sense of knowing, where they can predict how others will act within this context, in a flexible way, so that they can then also enact a set of understood behaviours.

\subsection{Youtien Hsing}

I think this studying the construction industry is a wonderful idea with a lot of potential. I'm just curious about this installation of technologies aspect. I think the next question that I would ask is: what makes them, then adopt new technology, because there are new buildings that do use newer technology.

\subsection{Nicole Biggart}

In fact there are new technologies, where they are adopted, and what we found was that by and large, these 'demonstration' projects are typically done in projects where it is an owner-occupied building. Government buildings are very innovative-they pay the money, they get what they want. And, in those sorts of buildings like a corporate headquarters, where it becomes an icon, where it becomes a representation of who or what that corporation represents, then they will pay for it. We visited the GAP headquarters building, 901 Cherry, in San Bruno, which has grass on the roof-it has all kinds of energy efficient properties to it. But that building would make no sense if you were going to try to sell it, because you could never get your money back as an investor. 


\subsection{Youtien Hsing}

There seems to be a major gap between the building technologies sector and the building construction sector - they seem to be following different logics.

\section{The career of the concept of embeddedness}

\subsection{Gillian Hart}

I'd like to bring the conversation back to embeddedness. Mark's comments offered an interesting account of how the paper emerged, but the question he did not answer was why it became so influential. Part of what got lost in the whole discussion was Polanyi's concept of the double movement. It is precisely this concept that helps us understand why the more static concept of embeddedness became influential. I would posit that two key events in the early 1990s helped to move that along. The first was the debate about the developmental state, associated in particular with Peter Evans (Evans, 1995), and the role of the state in the economy. Neo-liberals claimed that the East Asian miracles were market led. The notion of embeddedness was used to shore up the counter-argument about the active role of the state in the context of Asia.

Then the second really important way in which the double movement lets us understand why this concept became important was the idea of social capital. In 1993 Putnam's book came out (Putnam, 1993), and it was in 1995 that Serageldin was appointed Vice President for Environmentally and Socially Sustainable Development at the World Bank, and produced the first World Bank document that uses the concept of social capital (Serageldin, 1995). This occurred within the context of the Bank's shift towards environmental concerns, which as Robert Wade has shown, was pushed along by outside pressures. It was after the Asian financial crisis that social capital really came to the fore. It is the context of concern about the shift to neo-liberalism and the counter-movement that responds to it that the static notion of embeddness then gets deployed in the project of how can we institute a 'kinder, gentler' capitalism that's really coming out of the World Bank.

It seems to me that is where there really are two pathways out of Polanyi. The one is neo-Weberian that then gets instituted within the Bank. The other asks a more Marxist set of questions that have to do with the slippages and contradictions that emerge within the 'neo-liberal thrust' of the 1980s and 1990s.

\subsection{Mark Granovetter}

Let me say a few things about social capital. I was really involved in its birth. Robert Putnam held a series of planning meetings in the late 1980s and early 1990s. 
Of course he did not invent the concept. It goes back, certainly to Bourdieu. It is possible that the economist, Glen Loury, may have used it earlier, but Bourdieu gave it much more conceptual development. Then, James Coleman used it in the 1980s. But Bob Putnam was the main social capital entrepreneur, and brought it to the attention of the World Bank, which he did in a very entrepreneurial way. He organized a series of planning meetings in the early 1990s to which he invited people whom he considered to be loosely associated with the concepts that led to the idea of social capital. I was at those, as was Theda Skocpol, Doug North and various others. I think that although we never quite dissuaded him from launching this social capital ocean liner, at least we got him to think through some of the issues about whether it was always a good thing; whether there might not be situations where one group's social capital would be another group's social demise; to try to think about the fact that there were conflicts of interest in society-whether you conceptualize that in a Marxist or a non-Marxist way.

There is an idea that social capital is always a good thing, like chicken soup. I think that's the way the foundations thought of it. No matter what social ills there were, you could just give a big dose of social capital and that would take care of it. It was particularly popular because it contained a notion of private ordering, that if you could just encourage social capital, then the state could stand back. So it had some appeal for conservatives, and it had appeal for some economists. I think we moderated some of the ways that Bob Putnam used it. But he didn't follow all of our advice.

About Peter Evans, you are quite right. He used embeddedness as a way to rebut this neo-liberal argument about the state; that it all came out of the market. He wanted to show that some kinds of states do not retard development but actually can be 'midwives' or 'demiurges'. So there's a question of whether his use of embeddedness is static. I think the sense in which it was static was in that Peter didn't look carefully at why the bureaucracies he was studying were so well connected into the business world, why they were autonomous and how that changed over time. He lacked a dynamic argument about that. There is nothing inherent in ideas about social networks or embeddedness that makes you overlook that. It is just that Peter had three countries, and one very complicated industry, and that was a lot on his plate. I think he did a wonderful job explaining the nature of the bureaucratic state and giving a neo-Weberian account to explain under what circumstances states can be developmental. Certainly, the logical next step is to ask how state bureaucracies become autonomous, and how they become embedded with the business world, and how that can change over time. How is business embedded within itself? Why are different fractions of the state apparatus at odds with one another? You do need a dynamic argument, and that has to be founded in institutional analysis. A structural analysis alone will not provide the answer, though it may give some clues. All of these things have to go together. So I agree with your general framework. 


\subsection{Greta Krippner}

I want to take a minute to respond to Mark and Fred's comments. First of all, Mark, I think that you have provided a useful clarification that you were using this concept in your own way, and not as a borrowing or appropriation from Polanyi. Nevertheless, I think I was aware of that when I read your piece, and in a sense that is why in the paper (Krippner, 2001) I draw on Peggy Somers and her idea of doing a historical sociology of concept formation. Peggy has the idea that just as we've become very accustomed in the social sciences to thinking that data are theory laden, so we need to also think of concepts as history laden. I think there is a danger that when we are not always working out that history, we run the risk of subverting, or just missing the original intentions of the concept. That can be a sin of omission as well as commission, as seems to be the case here.

Secondly, in reference to the Armani suit, I need to clarify that the critique in my paper is directed at the way the field of economic sociology has developed. There is a dual critique: of Mark's paper, and of the way the field has developed. In that context, I think it is not an exaggeration to say that the structural aspect has been privileged in economic sociology, particularly as practised by network theorists such as Baker and Burt. This is explicit in their work, although perhaps not in your subsequent work. I did suggest in my paper that one could draw at least a loose parallel between Parsons' strategy of developing sociology as an academic discipline $v i s$-à-vis economics and your own strategy of establishing economic sociology as a discipline, also vis-à-vis economics some 50 years later.

Finally, I agree with Fred that we should not abandon the embeddedness concept. It is problematic, but it is still very useful. I am not suggesting it should be abandoned. 'Embeddedness' is so ubiquitous, it would be hard to get rid of it even if we wanted to. I am suggesting that it is necessary to liberate concepts from their intellectual antecedents, and in this context that means continually trying to problematize the separation of the economic from the social that I argue is contained within the concept-just as you sensitized us to the atomism that was lingering in sociology.

\section{Economics and economic sociology}

\subsection{Giovanni Arrighi}

The entire field of economic sociology, particularly the more recent work, has been constructed as a response to the hegemony of the economists. This is not a good starting point. As Terence Hopkins used to remind us all the time, the economy, in Polanyi's sense, has nothing to do with economics. Economists do not deal with the economy. They deal with abstract mathematical models that have nothing to do with it. 
The economy, for Polanyi, concerns the procurement of means of livelihood and the cooperation that such procurement involves. Polanyi contrasts this conception of the economy with economics as the study of 'economizing. This behaviour corresponds to Marshall's principle of substitution. It presupposes, and in turn activates, competition, disrupting the cooperation on which the procurement of means of livelihood is based. This a-social, nay, anti-social notion of the economy is what economists theorize.

In The Protestant Ethic (1958 [1904-5]) Weber tells a story that provides an excellent illustration of the relationship between Polanyi's notion of the economy and the economists' notion of economizing. The story is about a village of weavers who all produce the same thing, and therefore, according to the economists' view of the world, should be competing fiercely with one another. In Weber's historically far more accurate account, in contrast, the weavers are not competing at all. Rather, they are cooperating with one another in reproducing customary arrangements that enable each and all of them to procure means of livelihood without sacrificing their lives to work. Their purchases and sales give rise to and reproduce a system of exchanges - a 'market' - in which they are all 'embedded' and which is in 'equilibrium'. But the equilibrium is based on a generalized respect for customs and conventions, not on the economists' relentless competition of all against all. It is a social equilibrium.

In Weber's story, this equilibrium is broken when a young man comes along who breaks existing customs and conventions, by linking rural producers directly to urban wholesalers and consumers and thereby bypassing the weavers in the village. He is an 'economizer' (he saves on transaction costs). But he is also a socially deviant innovator. By raising the price of the villagers' inputs and depressing the price of their outputs, the young man forces them to compete with one another, disrupting their established ways of life and destroying the old system of procurement.

What this story underscores is that markets are simultaneously systems of cooperation and competition, systems of procurement and of substitution, but whatever they are they are social systems based on the reproduction/disruption of customs and conventions. They are not the kind of a-social, a-historical markets economists talk about-markets in which only competition rules, and only the number of participants in the market determines the intensity of the competition. I do not see what economic sociology has to gain by insisting on talking to economists who are on a totally different wavelength and have no interest in economies as historical social systems.

\subsection{Nicole Biggart}

Let me respond to that. I think that was true for 10, maybe 15, years. But it is not true any more. That was a period of identity formation for economic sociologists, and 
that identity was forged by saying: 'we are not economists', and 'let us show how we are not economists'. Now we are entering a period in which we know we are sociologists who are studying the economy. I think that the new generation of graduate students knows they are economic sociologists. I think that was a necessary process to go through, but now we are past it.

\subsection{Fred Block}

I wanted to pursue Nicole's point. The contribution of economic sociology was historically necessary because the institutionalist tradition was being closed out of economics, and somebody had to know what was going on in the real economy. Economic sociology has created this extraordinary space for lots of concrete empirical studies - the global ethnography of what is happening on the ground in terms of how people achieve their livelihood. However, given the fundamental structures of power and ideology, there is always this powerful undertow; the division between the political and the economic - a division which is constantly maintained by the definition of the field of economics itself. I disagree that the solution is not to talk to the economists. I think the undertow is there inevitably. There is a pull towards economic sociology being a field that accepts the boundary between politics and economics. Given all the natural processes of career-building, that undertow is always going to be very strong. We need to push against it constantly. We cannot ever separate economic processes off from an analysis of politics, and the state.

\subsection{Nicole Biggart}

We did not address it in our paper, but the political conclusion of our analysis, which we did give to our funding agents, was that the market is not going to solve the problem. We could think of at least two possible solutions. One is to regulatelet the state demand certain standards that everybody has to observe. The other is to start a social movement, through the pension funds, to make investment in 'dirty' buildings something that is an anathema. So I think there is definitely a political consequence to that kind of analysis, because the market is not going to fix the problem.

\subsection{Margie Mendell}

Just to pick up on the discussion between Giovanni and Fred: economists are not listening to economic sociologists. I am an economist, and they don't talk to me. However, there is a conversation with economists in policy areas. So we should go outside the university to have the conversation, and it is there that people who are working in economic sociology or in socio-economics have much more credibility. 


\section{The concept of the market}

\subsection{Margie Mendell}

I have a question for Fred apropos Giovanni's comments about separating the economy off from culture, politics, rules and norms. I want you to come back again to the question of 'thin' and 'thick' embeddedness. Why is it necessary to address such issues through Polanyi, especially when there is such tension and contradiction in his work?

\subsection{Fred Block}

No, I was just trying to say that I took Greta as saying that this 'thin' concept of embeddedness still left the market processes to be conceived as asocial. And so I was saying that we needed to replace that 'thin' view of embeddedness with a 'thick' view of embeddedness that sees all markets, even the most impersonal, as deeply social, and deeply political and cultural.

\subsection{John Hall}

I should like to return to Nicole's expression: 'imagine a market'. I tried really hard to do that and could not. There's a lot of talk about their embeddedness without really talking about markets themselves. We should consider disestablishing 'market' as a central feature of economic sociology. When I heard your discussion of the construction trades, I thought you could leave out the word 'market' almost entirely, and it would not take one iota away from your analysis.

\subsection{Michael Burawoy}

What I find interesting in economic sociology turns out to be a discussion of exchange, whereas there used to be, before there was economic sociology, studies of production. That was always where I thought economic sociology belonged. The contact between production and exchange has been a non-issue. I noticed that the case studies we heard this morning were all about production. So there seems to be a misfit between the theorization in economic sociology, which has a lot to do with markets, and what these wonderful graduate students are doing. Ironically, the problem is Polanyi: he did not know anything about production!

\subsection{Tom Beamish}

It seems to me that we should distinguish two things. The market, as a reified empirical object, and the market as a reified abstraction within the minds of the people who are creating it. This is the tension that I have confronted over the last 
two years of becoming an economic sociologist. I feel as if I am always dealing with a market that is somewhere 'over here', whereas when I'm speaking to people in the field they say: 'you know, I've decided about financing in the first 10 minutes, and then we run through these formal methods of appraisal'. That tells me that the market is in here and between people who know one another, or at least are familiar with how those like them act. Hence, we should relocate the market inside the people who construct the marketplaces and not reify the concept as if it were external in that way that seems to be characteristic of economic or neoclassical analysis.

\subsection{Steve Vogel}

I should like to ask Mark how the IT revolution, and particularly the advances in electronic commerce are going to affect our research agenda over the long term. I would agree with your assessment that all markets are social, even ones that seem to be impersonal. At the same time, however, markets can be more or less social, and I think that an e-market is one that is much less social than many that we study. The research here is so interesting because it is tightly linked to people, and face-toface interaction, and so tightly linked to place. That does not disappear with an e-market, but we could expect the destruction of existing networks, and some dilution of the social aspects of market interaction.

\subsection{Mark Granovetter}

Well, we have many good studies of this, but it does come back to the issue that markets are not more or less social. They may be more or less personal. So, for example, if you look at a collection of transactions that take place over E-Bay, then they are mostly impersonal in the sense that, in the transactions with one another, people do not actually know each other. As I understand it, people collect information about those they deal with from all the others who post information about them. So it is mostly an impersonal market, but it is nonetheless social. There is a very complex set of social norms and social procedures that intercede when things go wrongwhen somebody, despite all of the elaborate precautions, commits fraud. So I think there is a tremendous opportunity for economic sociologists to take a look at this.

This is also related to what I said about MacKenzie and Millo's (2003) work on the CBOE, which at one level looks like a very impersonal market because a lot of it is computerized. In that same paper they have a very interesting discussion of the way official Black-Scholes formulae for valuing these options are used, which appears very technical. It turns out that whether they accurately predict what is going to happen with these markets depends on various self-fulfilling prophecies, and people have to act as if they are going to predict the results accurately. So I think, if anything, there is even more scope for economic sociology to do its work, but it cannot do it in the rudimentary social network form of 'this one knows 
that one' where you draw a picture and you measure those relations. You have to do an institutional analysis of where all this is coming from and what the larger financial and political structure is in which this is all embedded.

\subsection{Giovanni Arrighi}

I am against John's proposal to do away with markets. The problem is to study markets for what they actually are and how they actually do or do not function, rather than worry about what economists think and say about them. The strength of the economists is that they construct formally logical models. Our criticisms of these models tend to be methodological or descriptive. That's fine, but our criticisms are not going to have any effect on the economists. As Margie said, they are not listening, and they are not talking about the same things as we are. So the first thing is to be clear on what we are talking about and to study markets as they actually exist and function.

The other important issue is capitalism, and its relation to markets. Much of sociology has banned capitalism from its vocabulary. I have looked at the Handbook of Economic Sociology (Smelser and Swedberg, 1994), and found that capitalism is hardly mentioned. When it is mentioned, it is conflated with markets. As Fernand Braudel has demonstrated, this conflation is disastrous for a historical understanding of either markets or capitalism.

Equally important is a historical understanding of the relationship between markets and production. It is often forgotten that production is itself embedded in markets, and the distinction between the two is largely a question of analytical focus, of whether one focuses on sites of production or on the interactions and exchanges among those sites. Even then we should not forget that the carrying and storing of goods, which take place in the market, is a form of production in the sense that it involves human effort (labour) and adds both use and exchange value to the goods that are carried and stored. So, I am against John's proposal to drop the word 'market' because I wouldn't know how to designate crucial aspects of social and economic life.

\subsection{John Hall}

I would accept 'the circulation of goods' as opposed to 'market' or 'exchange.'

\section{Markets and economic sociology}

\subsection{Sean O’Riain}

Since this might be my last chance, I wanted to abuse my position as moderator. I think about the field of organizational sociology, which essentially, over time, 
started with bureaucracy and became more and more focused on what bureaucracies were embedded in-having multiple levels and so on. But in economic sociology, the focus is on markets and embeddness, and the two are seen either in this relationship or as polar opposites. But all kinds of organizational forms are embedded, and that's an issue that has kind of slipped by the wayside within economic sociology, I think it's fair to say. So then I guess my question would be: are bureaucracies embedded in different institutions than markets are? Obviously they're embedded in one another-is the nature of that embeddedness different-does that change? In terms of Polanyi's double movement, it wasn't a double movement between corporations, corporate bureaucracies.

\subsection{Nicole Biggart}

I want to take issue with the view that economic sociology is only about markets, or markets and firms. I think there is another growing area of economic sociology that deals with economic values, the relationship of economic phenomena to other social phenomena-like religion, and the family-looking at the connections between economic phenomena and other kinds of social phenomena, which I think is one of the differences when sociologists rather than economists look at the economy. Most economists try to explain one economic phenomenon with another: what is the relationship between production and tariffs, or between tariffs and trade. Sociologists tend to look at such things as the relationship between cultural values and consumption, and the way that our discipline has been organized leads us to treat things like consumption as cultural phenomena. The same thing can be said of the relationship between religion and consumption. That should also be in economic sociology. I think that an economic sociology that is concerned only with firms and markets, narrowly construed, does not begin to approach the analytical power that we offer. I think we shall have a more powerful voice when we show the value of a fuller explanation, and also when we get out of the self-defeating idea that we do our analyses and we avoid involvement in policy debates. Along with anthropologists, sociologists try to be purists, which I think is much to our detriment. If we want to leave those discussions to those who are not afraid to get inside those debates, we have lost the real power of our analyses.

\subsection{Greta Krippner}

I want to second what Nicole said about firms and markets as being an obsessively narrow construction of what we're about. In terms of embedding other kinds of organizations, I think that is a controversial issue. Mark mentioned Peter Evans's book on the state (Evans, 1985). What is interesting about his use of embeddedness is that, in this context, the concept avoids some of the problems that it encounters 
elsewhere in economic sociology. We need always to look at the context in which certain ideas are deployed and developed. He uses it very productively to talk about understanding how states promote different kinds of development projects.

\subsection{Fred Block}

I have to respond to Michael's observation that Polanyi did not understand anything about production. I think that Polanyi was trying to break away from the old Marxist essentialized distinction between the sphere of production and the sphere of exchange. I think that is one of his enormous strengths. Remember that in Marx, the idea is that capitalism is a mode of production that is distinguished from earlier modes of production by virtue of the absence of extra-economic coercion. Surplus value is extracted by means of an exchange between the worker and the capitalist. There may be an executive committee of the ruling class up there, but Marx gives a purely economic definition of the nature of this transaction. One of the implications of Polanyi's argument is that this is wrong: under capitalism there are the same forms of extra-economic coercion that existed in earlier modes of production. Indeed, Polanyi was wrong, as Peggy Somers and I show about the details of his analysis of Speenhamland and the events leading up to the 1834 Poor Law Reform (Block and Somers, 2003). However, the part of the argument that stands is his emphasis that the new Poor Law in 1834 established the conditions for the rise and expansion of the 'dark, satanic' mills. He is hardly somebody who 'doesn't know anything about production'.

\subsection{Michael Burawoy}

I wouldn't call them 'dark and satanic' - I mean, dark mills don't produce cotton.

\subsection{Fred Block}

The lighting was very bad in those days....

\subsection{Mark Granovetter}

... He meant dark in the metaphorical sense.

\subsection{Fred Block}

Ok, maybe it was dank.

But essentially Polanyi's idea was that under the Poor Law regime, the relationship between the worker and the employer was mediated through a political 
arrangement which provided workers with some degree of protection, some negotiating power. And it is very clear in the writings of the classical economistsit is very clear in Nassau Senior who drafted a part of the Poor Law report. What they objected to was precisely this idea that there was a political mediation that provided the workers with some kind of resources and negotiating power vis-à-vis the employer. So what 1834 was about was a disciplinary device, which said there was only going to be the market that mediates the relationship between worker and employer. The English working class recognized what was being done to them and they rose up and resisted this reform, including particularly the working class of the north, which had not even been to the same degree beneficiaries of the Poor Law. But they saw it as the effort to create a purely market-driven relationship between worker and employer. So, that's an argument about the bargaining power, the relative power between workers and employers. Central to Polanyi's whole analysis is some fundamental understanding about the labour process - the relative power of workers and capital, and how the specific forms of political structuring of the market effect and shape those relative amounts of power. And then obviously what the protective counter-movement did was to create a series of measures which shifted that bargaining power to some degree. So the idea that these students are analysing the production processes through the wrong set of lenses, I reject it!

\subsection{Mark Granovetter}

Let me try to sum all of this up. For me, embeddedness is very much like social capital in the sense that I take these as being umbrella concepts. Social capital I think of as not something you can measure-if you want to find out how much social capital there is - whether it is 4.4 over here and 4.6 over here - then I think you are on a fool's errand. To me social capital is an announcement that there is a situation here where there is going to be more cooperation than you would expect if you only looked at incentives, and your job is to figure out what are the factors that make it possible for people to have that level of cooperation which is beyond the purely rationalized incentive situation. The term social capital itself doesn't help you at all in figuring out what that is, and I just think that we should leave it at that.

I think embeddedness is like that, too. I do not see the point of trying to measure the amount of it in this situation compared with that situation. For me it is just an announcement, or a conceptual umbrella under which one should look into and think about what are the connections between economic activity and the social, the political, the institutional, the historical, the cultural elements that economic activity is mixed up with. So it is a sensitizing umbrella concept and that is how I have come to use it, because I think anything else will just get us into endless debates of the sort that we have just finished. 


\section{Cast of characters in the Embeddedness Symposium}

Giovanni Arrighi, Sociologist, Johns Hopkins. arrighi@jhu.edu

Tom Beamish, Sociologist, UC Davis. tdbeamish@ucdavis.edu

Nicole Biggart, Management and Sociology, UC Davis.nwbiggart@ucdavis.edu

Fred Block, Sociology, UC Davis. flblock@ucdavis.edu

Michael Burawoy, Sociologist, Berkeley. burawoy@socrates.berkeley.edu

Mark Granovetter, Sociologist, Stanford. mgranovetter@stanford.edu

John Hall, Sociologist, UC Davis.jrhall@ucdavis.edu

Gillian Hart, Geographer at Berkeley. hart@socrates.berkeley.edu

Youtien Hsing, Geographer at Berkeley. yhsing@socrates.berkeley.edu

Matt Keller, Sociology graduate student, UC Davis.mrkeller@ucdavis.edu

Greta Krippner, Sociology, UCLA.gkrippne@soc.ucla.edu

Marguerite Mendell, Co-director of the Karl Polanyi Institute and teaches in Community Studies at Concordia.mendell@vax2.concordia.ca

Sean O’Riain, Sociology, National University of Ireland, Maynooth.Sean.ORiain@may.ie

Preston Rudy, Sociology graduate student, UC Davis. porudy@ucdavis.edu

Steve Vogel, Political Scientist, Berkeley. Svogel@socrates.berkeley.edu

\section{References}

Block, F. (2003) 'Karl Polanyi and the Writing of The Great Transformation,' Theory and Society? Get reference from Fred

Block, F. (1990) Postindustrial Possibilities: A Critique of Economic Discourse, Berkeley, CA, University of California Press.

Block, F. and Somers, M. (2003) 'In the Shadow of Speenhamland: Social Policy and the Old Poor Law', Politics and Society, 31, 283-323.

Burawoy, M. (1979) Manufacturing Consent, Chicago, University of Chicago Press.

Burawoy, M. (1985) The Politics of Production, London, Verso.

Evans, P. (1995) Embedded Autonomy, Princeton, NJ, Princeton University Press.

Fligstein, N. (1996) 'Markets as Politics: A Political-Cultural Approach to Market Institutions', American Sociological Review, 61, 657.

Granovetter, M. (1985) 'Economic Action and Social Structure: the Problem of Embeddedness', American Journal of Sociology, 91, 481-510.

Granovetter, M. (1973) 'The Strength of Weak Ties'. American Journal of Sociology, 78, 1360-80.

Granovetter, M. (2002) 'A Theoretical Agenda for Economic Sociology'. In Guillen, M., Collins, R., England, P. and Meyer, M. (eds) The New Economic Sociology: Developments in an Emerging Field. New York, Russell Sage, pp. 35-59. 
Hirsch, F. (1976) Social Limits to Growth, Cambridge, MA, Hardvard University Press.

Keynes, J.M. (1919) The Economic Consequences of the Peace, London, Macmillan.

Krippner, G. R. (2001) 'The Elusive Market: Embeddedness and the Paradigm of Economic Sociology', Theory and Society, 30, 775-810.

Lutzenhiser, L., Biggart, N., Kunkle, R., Beamish, T. and Burr, T. (2001) 'Market Structure and Energy Efficiency: The Case of New Commercial Buildings', Available at http://ciee.ucop.edu/docs/market_struc.pdf

Mackenzie, D. and Millo, Y. (2003) 'Constructing a Market, Performing Theory: The Historical Sociology of Financial Derivatives Exchange'. American Journal of Sociology, 109, 107-145.

Otis, E. (2002) 'Embedding Service: Gender, Class, and the Moral Economy of the Socialist Work Unit in China', paper presented at the conference.

Polanyi, K. (1957) 'The Economy as Institute Process.' In Dalton, G. (ed.), Primitive, Archaic and Modern Economies: Essays of Karl Polanyi. Boston, Beacon, 1968, pp. 139-74.

Powell, W. W. and Smith-Doerr, L. (1994) 'Networks and Economic Life'. In Smelser, N. and Swedberg, R. (eds) Handbook of Economic Sociology, New York, Russell Sage, p. 371.

Putnam, R. (1993) Making Democracy Work: Civic Traditions in Modern Italy. Princeton, NJ, Princeton University Press.

Serageldin, I. (1995) Sustainability and the Wealth of Nations: First Steps in on Ongoing Journey. Washington DC, The World Bank Environmentally Sustainable Development Studies and Monograph Series, No. 5.

Silver, B. and Arrighi, G. (2003) 'Polanyi's Double Movement', Politics and Society, 31, 325-55.

Smelser, N. and Swedberg, R. (1994) Handbook of Economic Sociology, New York, Russell Sage.

Weber, M. (1958 [1904-]) The Protestant Ethic and the Spirit of Capitalism, New York, Scribners.

Zelizer, V. (1979) Morals and Markets: The Development of Life Insurance in the United States. New York: Columbia University Press.

Zukin, S. and DiMaggio, P. (1990) (eds) 'Introduction'. In Structures of Capital: The Social Organization of the Economy, Cambridge, Cambridge University Press, pp. 1-36.

Uzzi, B. (1997) 'Social Structure and Competition in Interfirm Networks: The Paradox of Embeddedness', Administrative Science Quarterly, 42, 63. 